\title{
Pasteurella multocida bacterial meningitis caused by contact with pigs
}

\author{
C. López ${ }^{1}$, P. Sanchez- Rubio ${ }^{2}$, A. Betrán ${ }^{1}$, R.Terré ${ }^{3}$ \\ ${ }^{1}$ Servicio de Microbiología, Hospital de Barbastro, Carretera de Tarragona-San Sebastián, \\ Barbastro, Huesca, Spain. \\ ${ }^{2}$ Servicio de Medicina Interna, Hospital de Barbastro, Carretera de Tarragona-San Sebastián, \\ Barbastro, Huesca, Spain. \\ ${ }^{3}$ Servicio de Otorrinolaringología, Hospital de Barbastro, Carretera de Tarragona-San \\ Sebastián, Barbastro, Huesca, Spain.
}

Submitted: June 15, 2011; Approved: September 10, 2012.

\begin{abstract}
Pasteurella multocida belongs to the normal flora of the respiratory and digestive tract of many animals. Animal exposure is a considerable risk factor for Pasteurella infection. P. multocida is the most common cause of local infection after an animal bite but is an unusual cause of meningitis. We present a case of bacterial meningitis by $P$. multocida in a 37-year-old man who worked in a pig farm and was bitten by a pig. The patient had a defect located in the lamina cribosa and this lesion could be the gateway of the infection, although in this case the infection could also be acquired through the pig bite. The bacteria was identified as P. multocida with the biochemical test API 20E (bioMérieux). In agreement with findings in the literature, the strain was susceptible in vitro to penicillin, ampicillin, cefotaxime, ceftriaxone ciprofloxacin, levofloxacin, imipenem and tetracycline.
\end{abstract}

Key words: Pasteurella multocida, bacterial meningitis.

A 37 years-old male was admitted to the Hospital of Barbastro (Huesca) with a 12-h history of headache, vomiting and fever. At admission, neurological, abdominal, cardiac, and pulmonary examination findings were normal. Lumbar puncture revealed cloudy fluid, 5300 cells $/ \mathrm{mm} 3$ (100\% polymorphonuclear), glucose $0 \mathrm{mg} / \mathrm{dL}$ (blood glucose $125 \mathrm{mg} / \mathrm{dL}$ ) and protein $510 \mathrm{mg} / \mathrm{dL}$. Gram stain revealed no bacteria. Blood cultures were then performed. Empirical treatment was started intravenously with ceftriaxone and vancomycin. By the next day he was afebrile and feeling better.

Within $24 \mathrm{~h}$, blood cultures yielded catalase-positive, oxydase-positive, gram-negative coccobacillus. The organism grew under both aerobic and anaerobic conditions but failed to grow on MacConkey agar. It was identified as $P$. multocida with the biochemical test API 20E (bioMérieux). The strain was susceptible in vitro to penicillin, ampicillin, cefotaxime, ceftriaxone ciprofloxacin, levofloxacin, imipenem and tetracycline. After culture results, treatment was continued only with ceftriaxone.
The patient was working on a pig farm and he had received a pig bite eight days ago. Four months ago, he was hospitalized for frontal headache and he was diagnosed for meningitis by Streptococcus suis.

Computer tomographic (CT) scan of the head indicated a partial condensation and widening of right ethmoidal cells indicated ethmoid sinusitis.

The recurrent meningitis and the $\mathrm{CT}$ data suggested that the patient had a defect located in the lamina cribosa and this lesion could be the gateway of the infection, although in this case the infection could also be acquired through the pig bite.

P. multocida belongs to the normal flora of the respiratory and digestive tract of many domestic livestock and wild animals (Francis, 1975). They can produce a spectrum of human diseases and because these are frequently serious diseases, $P$. multocida infection is considered an important zoonosis (Kimura, 2004). Animal exposure is a considerable risk factor for Pasteurella infection. Pasteurella multocida is known to form part of the normal microbiota

Send correspondence to A. Betrán. Servicio de Microbiología, Hospital de Barbastro, Carretera de Tarragona-San Sebastián (N-240), S/N, 22300 Barbastro, Huesca, Spain. E-mail: abetrane@salud.aragon.es. 
in the nasopharynx or gastrointestinal tract in many domestic and wild animals (Armstrong, 2000). In the case reported here, the patient had contact with pigs because he worked in a pig farm and he was bitten by a pig few days ago. The patient suffered from chronic sinusitis and a defect located in the lamina cribosa confirmed by detection of beta-2 transferrin in nasal fluid. The pathogen might enter the body directly from the upper respiratory tract or cutaneous wound caused by animal bite as a result of salivary colonisation (Henderson, 2010). The clinical progression and the recurrent meningitis in the past four months supported the former pathway. P. multocida appears to be an opportunistic pathogen and there have been cases of meningitis in the literature after skull fractures, cranial surgery, etc. (Yagupski, 1985).

The usual antibiotic therapy for pasteurellosis relies on Blactams (Ruiz-Irastorza, 1995). The organism is usually well covered by most of the empirical treatments currently used. Treatment is optimized by the early identification of P. multocida and rapid effective treatment with penicillin, ampicillin or a third-generation cephalosporin.

$P$. multocida infections have been reported in compromised hosts as well as in healthy individuals and must be suspected in healthy patients who have a history of animal exposure and present with systemic symptoms. Increased contact with domestic animals might contribute to the increasing frequency of reports of $P$. multocida infection. Defects located in lamina cribosa may favour recur- rent meningitis. In this case, Pasteurella is part of the environmental microbiota of the patient and his work can be considered a risk factor for developing severe infections such as meningitis. For diagnosis of $P$. multocida infections it is essential to obtain a detailed patient history about animal exposure and provide this information to the clinical microbiology laboratory.

\section{References}

Armstrong GR, Sen RA, Wilkinson J (2000) Pasteurella multocida meningitis in an adult: case report. J Clin Pathol 53:234-235.

Francis DP, Holmes MA, Brandon G (1975) Pasteurella multocida infections after domestic animal bites and scratches. JAMA 233:42-45.

Henderson SR, Shah A, Banford KB, Howard LS (2010) Pig trotters lung-novel domestic transmission of Pasteurella multocida. Clin Med. 10:517-518.

Kimura R, Hayashi Y, Takeuchi Tet(2004) Pasteurella multocida septicemia caused by close contact with a domestic cat: case report and literature review.J Infect Chemother 10:250-252.

Ruiz-Irastorz G, Garea C, Alonso JJ (1995) Septic shock due to Pasteurella multocida subspecies multocida in a previously healthy woman. Clin Infect Dis 21:232-234.

Yagupski P, Simo A, Gorodischer R (1985) Pasteurella ureae meningitis as complication of skull fractures. Eur J Clin Microbiol 4:589-590.

All the content of the journal, except where otherwise noted, is licensed under a Creative Commons License CC BY-NC. 